\title{
Numerical Analysis of the Turbulent Flow around DTMB 4381 Marine Propeller
}

\author{
Kyaw Kyaw $^{\# 1}$, Ye Jinming ${ }^{* 2}$ \\ \# Researcher, Naval Dockyard, Myanmar \\ *Professor, Department of Ship and Ocean Engineering, Naval University of Engineering, Wuhan, China \\ 1stakyawkyawsmtu@gmail.com
}

DOI: $10.31364 / \mathrm{SCIRJ} / \mathrm{V} 9.103 .2021 . \mathrm{P} 0321846$

http://dx.doi.org/10.31364/SCIRJ/v9.i03.2021.P0321846

\begin{abstract}
This article presents a numerical analysis of a turbulent flow past DTMB 4381 marine propeller by the means of RANS approach; the propeller designed at David Taylor Model Basin in USA. For numerical evaluation of propeller open-water characteristics, the moving reference frame approach was used. Total force and moment acting on blades, as well as average force distributions in one revolution on propeller disk, are obtained for each case of advance ratio $(J)$. The solver used in this study was the commercial package Star-CCM+ from SIEMENS. The computed results are compared with available experimental data and discussed.
\end{abstract}

Keywords - RANS, marine propeller, Star-CCM+, CFD

\section{INTRODUCTION}

Because of the ship's stern geometric form, the velocity field is considered as non-uniform near the propeller [1]. Nowadays, numerical methods are widely used to calculate the flow in the said region such as RANS and LES methods with the help of commercial software or open source programs. With the help of the latest computer performance, the numerical methods are becoming more and more widely used and the results are accurate than before.

Computational fluid dynamics (CFD) are becoming a widely used method for propeller test in the propeller predesign stage. Although there are many different propeller simulation techniques, the RANS method are regarded as the most favourable because of its low computational times.

Hopefully, the results in this paper can be a good reference for propeller design because there will be a validation process of the results compared with the information from David Taylor Naval Ship Research and Development Centre (DTNSRDC). It's concerned that this paper is a CFD application of propeller open water test and the results are compared with experimental data. As a result, there may be different results because of different settings of CFD software. But compare with other methods and using a larger database, there is a way to get propeller characteristics as accurate as possible.

The marine propeller is a complex geometry; with profiles for different sections, chords lengths, and geometric pitch angle of variable pitch [2]. The RANS method has proved its reliability to predict the viscous flow around marine propeller. The quality of the mesh and turbulence modelling are the main obstacles influential on the accuracy of results [2].

\section{GEOMETRIC CHARACTERISTICS OF DTMB 4381 PROPELLER}

Boswell (1971) presented cavitation tunnel and open water results for a series of skewed propeller. One of them is (DTNSRDC) DTMB 4381 propeller (0 degree skew). It's a five blades propeller with a variable pitch and a diameter of $\mathrm{D}$ $=0.3048 \mathrm{~m}$; an $\mathrm{AE} / \mathrm{AO}$ of $0.725 ; \mathrm{NACA} \mathrm{a}=0.8$ mean lines with NACA 66 modified profiles.

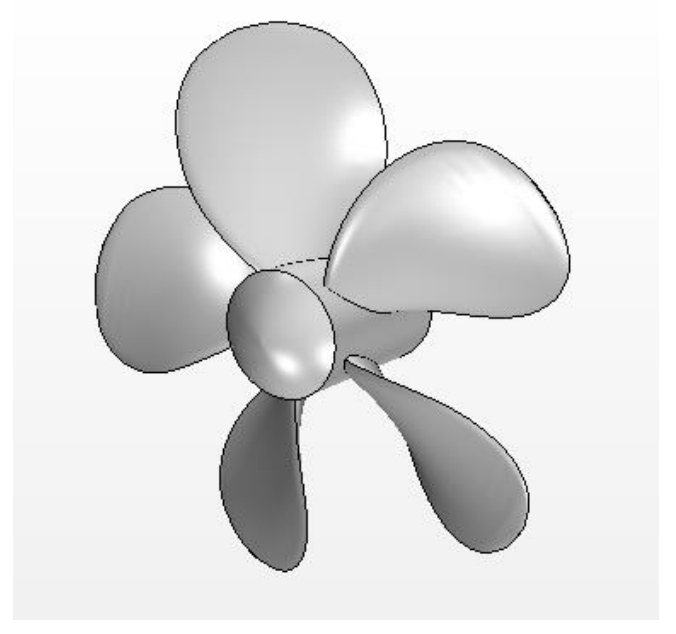

Fig.1 Geometry of DTMB 4381 propeller

TABLE I

GEOMETRY OF ORIGINAL DTMB 4381 PROPELLER

\begin{tabular}{|r|r|r|r|r|}
\hline \multicolumn{1}{|c|}{$\mathbf{r} / \mathbf{R}$} & \multicolumn{1}{c|}{$\mathbf{c} / \mathbf{D}$} & \multicolumn{1}{c|}{$\mathbf{P} / \mathbf{D}$} & \multicolumn{1}{c|}{$\mathbf{t}_{\mathbf{m a x}} / \mathbf{D}$} & \multicolumn{1}{c|}{$\mathbf{f}_{\mathbf{m a x}} / \mathbf{c}$} \\
\hline 0.2 & 0.174 & 1.332 & 0.0434 & 0.0351 \\
\hline 0.25 & 0.202 & 1.338 & 0.0396 & 0.0369 \\
\hline 0.3 & 0.229 & 1.345 & 0.0358 & 0.0368 \\
\hline 0.4 & 0.275 & 1.358 & 0.0294 & 0.0348 \\
\hline 0.5 & 0.312 & 1.336 & 0.024 & 0.0307 \\
\hline 0.6 & 0.337 & 1.28 & 0.0191 & 0.0245 \\
\hline 0.7 & 0.347 & 1.21 & 0.0146 & 0.0191 \\
\hline 0.8 & 0.334 & 1.137 & 0.0105 & 0.0148 \\
\hline 0.9 & 0.28 & 1.066 & 0.0067 & 0.0123 \\
\hline 0.95 & 0.21 & 1.031 & 0.0048 & 0.0128 \\
\hline 1 & 0.001 & 0.995 & 0.0029 & 0 \\
\hline
\end{tabular}

\section{MATHEMATICAL FORMULATION}

The turbulent viscous flow around the propeller is described by the Navier-Stokes and turbulent equation as; 


$$
\begin{gathered}
\frac{\partial u_{i}}{\partial t}=0 \\
\frac{\partial\left(\rho u_{i}\right)}{\partial t}+\frac{\partial\left(\rho u_{i} u_{j}\right)}{\partial x_{j}}=-\frac{\partial P}{\partial x}+\frac{\partial}{\partial x_{j}}\left(\mu \frac{\partial u_{i}}{\partial x_{i}}-\rho \overline{u_{1}^{\prime} u_{j}^{\prime}}\right)
\end{gathered}
$$

\section{A. The Standard $k-\varepsilon$ Turbulence model}

The Wilcox [3] k- $\varepsilon$ two-equation model is given by the following turbulent kinetic energy and dissipation equations:

$$
\begin{aligned}
& \frac{\partial(\rho k)}{\partial t}+\frac{\partial\left(\rho k u_{i}\right)}{\partial x_{i}}=\frac{\partial}{\partial x_{j}}\left[\left(\mu+\frac{\mu_{t}}{\sigma_{k}}\right) \frac{\partial k}{\partial x_{j}}\right]+P_{k}+P_{b}-\rho \epsilon-Y_{M}+S_{k} \\
& \frac{\partial(\rho \epsilon)}{\partial t}+\frac{\partial\left(\rho \epsilon u_{i}\right)}{\partial x_{i}}=\frac{\partial}{\partial x_{j}}\left[\left(\mu+\frac{\mu_{t}}{\sigma_{\epsilon}}\right) \frac{\partial \epsilon}{\partial x_{j}}\right]+C_{1 \epsilon} \frac{\epsilon}{k}\left(P_{k}+C_{3 \epsilon} P_{b}\right)-C_{2 \epsilon} \rho \frac{\epsilon^{2}}{k}+S_{\epsilon}
\end{aligned}
$$

Explicit details for the model can be found in [4] and [5].

\section{NUMERICAL SETUP}

\section{A. Test Cases}

The open water simulation is carried out for the same conditions as experiment with different advance coefficient $\mathbf{J}$ from 0.4 to 1 with step equal 0.1 . The revolution of propeller was kept constant $\mathrm{n}=15 \mathrm{rps}, \mathrm{J}$ is changed by varying advance velocity. The water parameters (density, viscosity) corresponded to real value (water density $\rho=998.67 \mathrm{~kg} / \mathrm{m}^{3}$, kinematic viscosity of water $\mathrm{n}=1.070 \times 10^{-6} \mathrm{~m}^{2} / \mathrm{s}$ ).

\section{B. Computational Method}

For the computations of propeller open water characteristics, the rotating reference frame approach was used. This approach is suitable for open water analysis and the result is almost similar to the actual propeller rotation. At the same time the computational time is reduced and the convergence is faster [6]. The solver used for the computation in this study is the commercial package Star-CCM+ Version 13.02 from SIEMENS [7].

\section{Domain size and boundary conditions}

The computation domain size and boundary conditions are important factors that affect the numerical results. The size of computation domain should be defined in a way to ensure uniform incoming flow upstream of the propeller and to avoid any reflections downstream of propeller. Based on the recommendations given by ITTC [8], the computation domain for open-water propeller simulation is cylindrical and characterized by the following dimensions, expressed as multiples of propeller diameter D. The inlet was located at a distance of $5 \mathrm{D}$ from the midpoint of the chord of the root section, while the outlet was located 13D from the propeller axis, respectively. Boundary condition: velocity inlet condition was used on inlet. Pressure outlet condition was applied on outlet. Symmetry plane condition was used on outer boundary. No-slip wall condition is applied for the propeller, hub and shaft. The selected domain and boundary condition for propeller open water simulation is illustrated in Fig. 2.

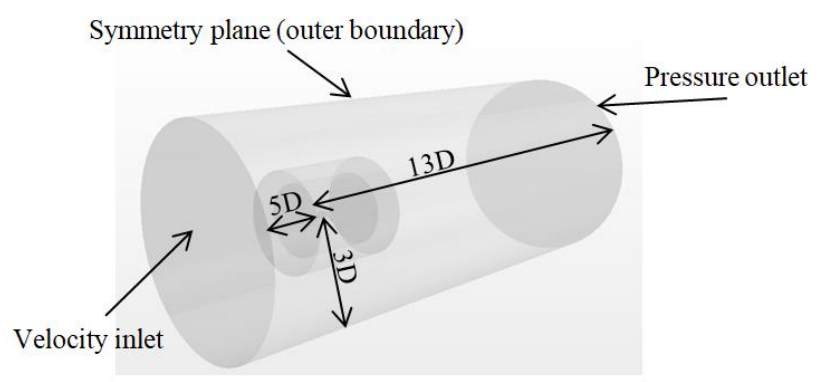

Fig. 2 Domain and boundary condition for propeller open water simulation

\section{Mesh generation}

The simulation was performed on one of three types of core volume meshes supported by Star-CCM+: trimmed cell mesher. To avoid the unnecessary time consuming and computing, fine grid is not used in the region in front and behind the propeller where is very far from the propeller. Local refinement was applied around the propeller, especially the regions of leading edge, trailing edge and propeller blade tips [9]. To capture the exact flow behaviour near the walls, prism layer was used for resolving the boundary layer.

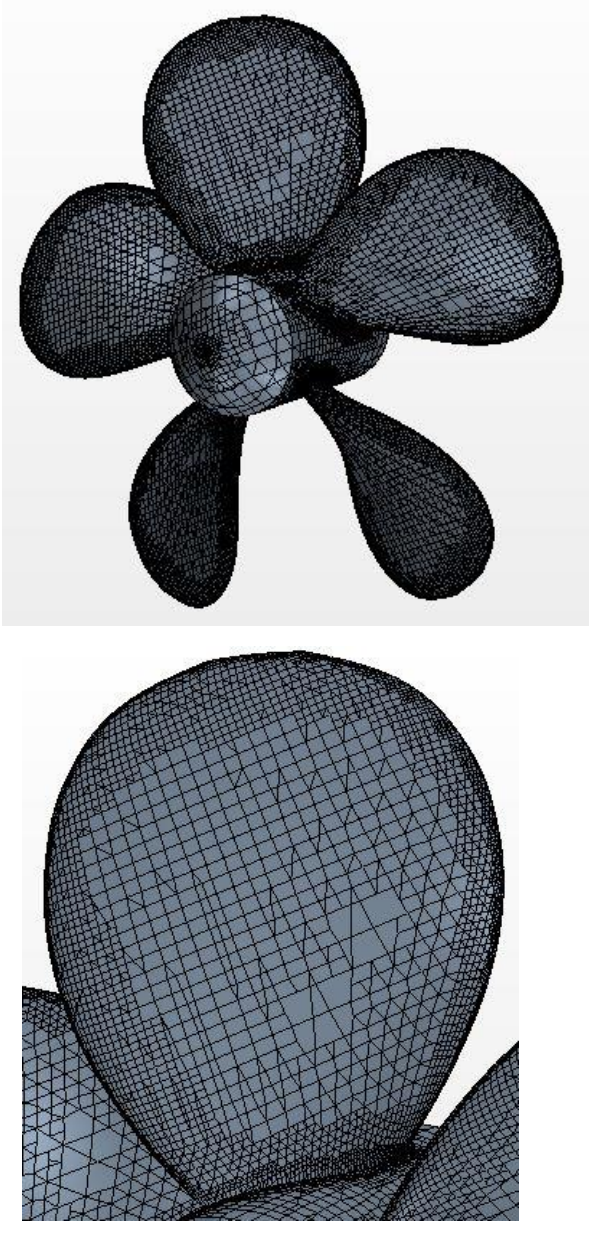

Fig. 3 Mesh for blade 
NUMERICAL AND EXPERIMENTAL RESULTS

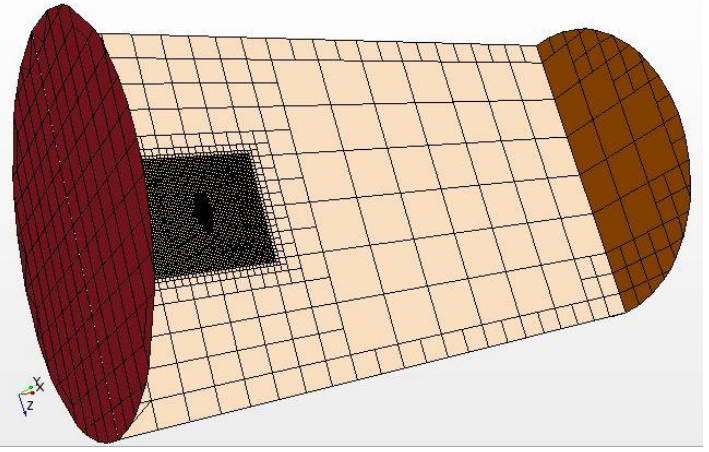

Fig. 4 Volume mesh for the whole simulation

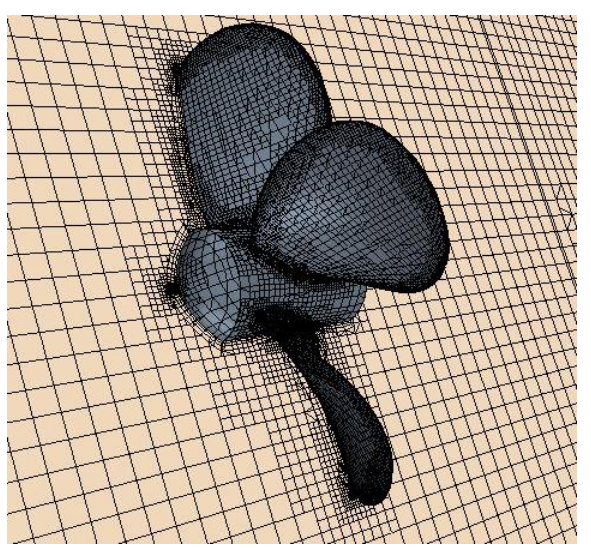

Fig. 5 Volume mesh around DTMB 4381 model

\section{E. Physics model}

The three-dimensional incompressible viscous Reynolds Averaged Navier Stokes (RANSE) equation for steady flow is applied to calculate flow field around propeller. For choosing appropriate turbulence model, it is still a point of concern due to the fact that there are no 'universal' turbulence model has been developed [10]. Two equation models K-Epsilon (Realizable K-Epsilon Two-layer) is used in this study.

\section{INITIAL CONDITIONS}

Steady numerical simulating was achieved for a wide range of advance coefficients $\mathrm{J}$ between 0.4 and 1 . The rotational speed of the propeller model DTMB 4381 was fixed at $n=15$ rps.

TABLE II

INITIAL CONDITIONS OF DTMB 4381

\begin{tabular}{|c|c|}
\hline $\mathrm{D}[\mathrm{m}]$ & 1 \\
\hline $\mathrm{n}[\mathrm{rps}]$ & 15 \\
\hline $\mathrm{Va}[\mathrm{m} / \mathrm{s}]$ & 12 \\
\hline $\mathrm{J}[-]$ & 0.8 \\
\hline $\mathrm{KT}[-]$ & 0.252 \\
\hline $10 \mathrm{KQ}[-]$ & 0.492 \\
\hline
\end{tabular}

\section{OPEN WATER RESUlTS}

The numerical results are compared with experiment for a wide range of advance coefficients $J$. The calculated hydrodynamic characteristics $\left(\mathrm{K}_{\mathrm{T}}, \mathrm{K}_{\mathrm{Q}}\right)$ are shown in Fig. 6. The mean error estimated for the thrust coefficient $\mathrm{K}_{\mathrm{T}}$ is $1.91 \%$ and $3.57 \%$ for torque coefficient $\mathrm{K}_{\mathrm{Q}}$.

\begin{tabular}{|c|c|c|c|c|}
\hline J & KT EXP & KT RANS & 10KQ EXP & 10KQ RANS \\
\hline 0.4 & 0.428 & 0.427 & 0.729 & 0.757 \\
\hline 0.5 & 0.388 & 0.385 & 0.673 & 0.696 \\
\hline 0.6 & 0.341 & 0.340 & 0.612 & 0.635 \\
\hline 0.7 & 0.298 & 0.295 & 0.549 & 0.571 \\
\hline 0.8 & 0.253 & 0.248 & 0.486 & 0.504 \\
\hline 0.9 & 0.208 & 0.199 & 0.419 & 0.431 \\
\hline 1 & 0.157 & 0.149 & 0.341 & 0.353 \\
\hline
\end{tabular}

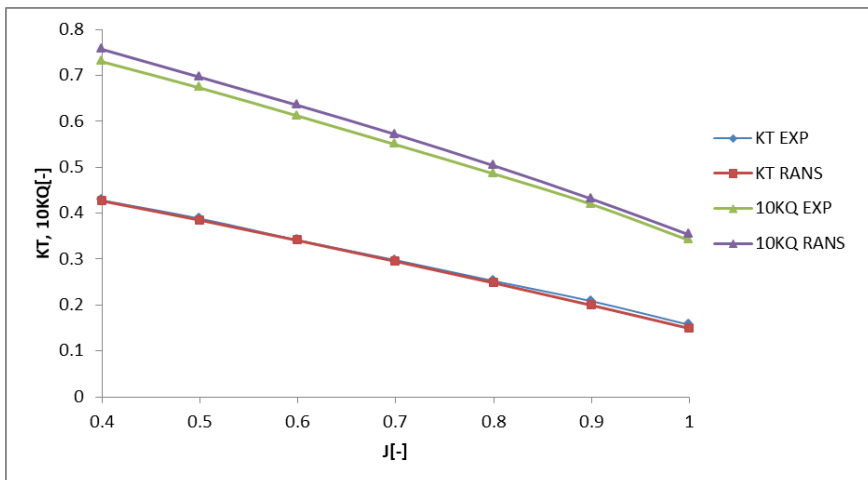

Fig. 6 Comparison of open water characteristics for DTMB 4381 propeller

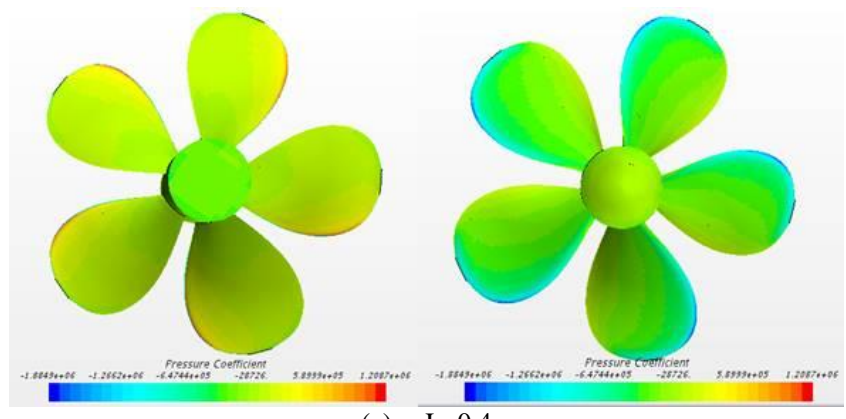

(a) $\mathrm{J}=0.4$

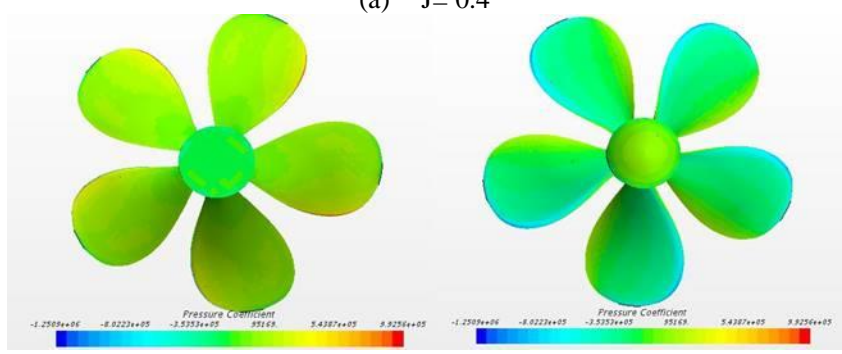

(b) $\mathrm{J}=0.6$

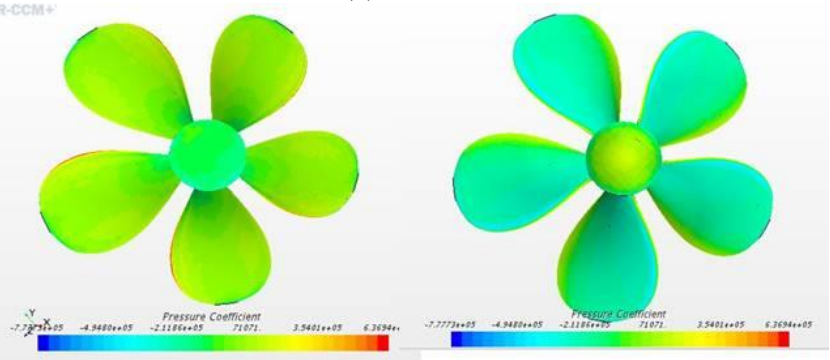

(c) $\mathrm{J}=0.8$

TABLE III 


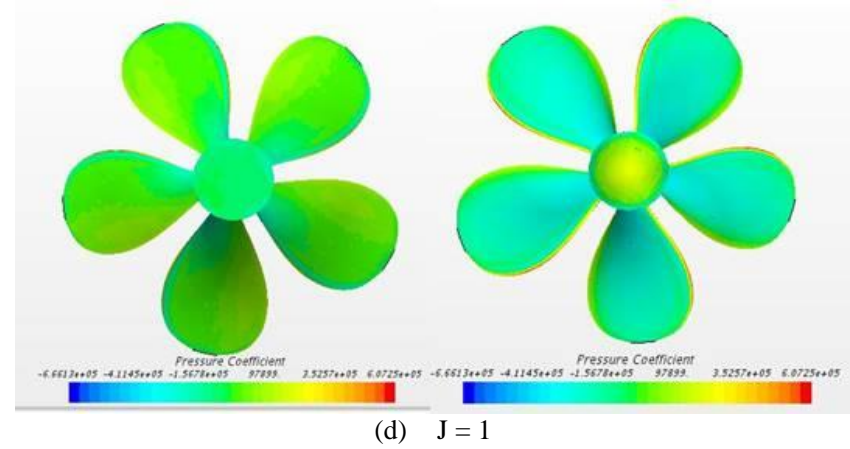

Fig. 7 Pressure distribution on the pressure side and blade suction

Fig. 7 shows the pressure coefficient contour $C_{P}$ for different advance coefficient $\mathrm{J}$. Because the flow is uniform at the inlet, the pressure coefficient is constant over for the blades as shown in Fig. 7. But it changes if the propeller is operating behind the ship hull [11].

\section{CONCLUSION}

In present study, the three-dimensional incompressible viscous steady RANSE method has been applied to predict propeller open water characteristics. The following conclusions can be made:

(a) The results of calculating propeller hydrodynamics characteristics depend on the selected mesh type, mesh density and turbulence model.

(b) The computational fluid dynamics (CFD) results were compared with the experiment data and the difference is less than $4.89 \%$ for $\mathrm{K}_{\mathrm{T}}$ and $4.01 \%$ for $\mathrm{K}_{\mathrm{Q}}$

\section{REFERENCES}

[1] Architecture Navale Dominique Presles, Edition de la Villette, Paris 2005.

[2] Marine propeller and propulsion John Carlton, 2nd Edition Great Britain, MPG Books Ltd, Bodmin Cornwall, 2007.

[3] Wilcox, D.C., Turbulence Modeling for CFD, 2nd Ed., DCW Industries, Inc., La Canada, CA, 1998.

[4] Wilcox, D.C., Turbulence Modeling for CFD, 3rd Ed., DCW Industries, Inc., La Canada, CA, 2006.

[5] Menter, F., 1994, Two-equation eddy-viscosity turbulence model for engineering applications, AIAAJ., 32(8): 1598-1605.

[6] T.N. Tu, N.M. Chien, comparison of different approaches for calculation of propeller open water characteristic using RANSE method, Naval Eng. J. 130 (1) (2018), 1 March 2018, 105-111(7).

[7] CD-ADAPCO. User Guide STAR-CCM+, Version 13.022018

[8] Practical Guidelines for Ship Self-Propulsion CFD, ITTC Recommended Procedures and Guidelines, 7.5-03-03-01, 2014.

[9] T. Bugalski, P. Hoffmann, Numerical simulation of the self-propulsion model tests, In Second International Symposium on Marine Propulsors smp, 2011.

[10] Practical Guidelines for Ship Self-Propulsion CFD, ITTC Recommended Procedures and Guidelines, 7.5 - $0302-03,2011$

[11] S.E. Belhenniche "Application of CFD in Analysis of Steady and Unsteady Turbulent Flow Past a Marine Propeller," International Conference of Heat and Mass Transfer ICHMT Palermo (Italy) 2012. 